\title{
Unlocking Opportunity at Texas Christian University: Are Income Share Agreements the Master Key?
}

\author{
Matt Williams
}




\section{Abstract}

As the nation's growing student debt obligations surmount $\$ 1.6$ trillion, some post-secondary education institutions are investigating innovative solutions for college financing to replace traditional loans. Income Share Agreements (ISAs) represent a popular strategy for some trade and state universities; through legal contracts, these institutions assume the burden of remaining education costs after grants and scholarships in return for a predetermined percentage of the student's future income over a specified time period. This thesis will investigate the viability of ISAs specifically at private, nonprofit, four-year institutions, using Texas Christian University (TGU) as a case study. Using a multivariate distribution of correlated stochastic variables, Monte Carlo simulation generated thousands of possible net present value (NPV) scenarios for ISA contracts with the Neeley School of Business, the site of a potential pilot program. Most business major ISA contracts demonstrated a probability greater than 98\% to return a positive NPV. These findings solidify recommendations to implement such a pilot program within the Neeley School of Business with the hopes of expanding these financial aid tools to all major programs in future years. An income share program at TCU could not only unlock opportunity but also maintain the university's financial stability in a time of economic downturn.

\section{Introduction}

The concept of Income Share Agreements (ISAs) was first introduced by Milton Friedman in 1955 when he argued that college educations could be funded via "equity investments." Equity investments outline the idea that "[investors] could 'buy' a share in an individual's earning prospects to advance the funds needed to finance his training on condition he agree to pay the lender a specified fraction of his future earnings" (About ISAs 2020). The first practical application of this theory was observed in the 1970s at Yale University, through a program that allowed students to collectively repay their class's tuition post-graduation. Eventually, the model failed to prove its sustainability, and in 1999, Yale abandoned the program and forgave all outstanding obligations (About ISAs 2020). The early application of ISAs failed to include many stipulations protecting lower and middle-income students, such as repayment caps and minimum income thresholds. In addition, Yale's program included a clause allowing high earners to prepay and opt out of the program early, leaving lower-income students to complete the group repayment alone (Levin, 2018).

Despite an unsuccessful debut, ISAs have become increasingly popular today, even as student debt has grown to unimagined levels. Purdue University, led by President Mitch Daniels, launched the first major ISA program, called "Back a Boiler" in 2016. Similar to Back a Boiler, many ISA programs in the United States are found at large public universities or trade schools, where government funding is supplemental or exit salary data is more stable. Due to the uncertainty of repayment and starting salary levels, risk-averse non-profit, private institutions have yet to fully accept the feasibility of ISAs.

This thesis will investigate how private, four-year universities can strategically pilot an ISA program that will be poised to succeed and maximize accessibility for middle-income students. Using Texas Christian University (TCU) as a case study, a sustainable ISA pilot program model is the target of this research. 


\section{Research Questions}

The focus of this thesis will be to provide background information, analysis, and a detailed strategy to answer the following questions:

1. Are Income Share Agreements a viable and sustainable financial aid alternative for non-profit, private, four-year universities in the United States?

2. What strategies might these universities employ to pilot an ISA program in order to mitigate risks?

3. Would an ISA program be viable at Texas Christian University, and if so, how might the institution design a program fit for the university's students?

\section{Literature Review}

\section{Income Share Agreements}

Milton Friedman initially wrote of "equity investments" for the funding of higher education in 1955; however, his conceptual frameworks were never tested until the 1970s with Yale University's cohort-based Income Share Agreement plan. A group of students would join together in a contract to collectively repay the cost of education based on a percentage of their future pre-tax income. However, the majority of the financial burden fell to the middle-income graduates, while others repaid little of their cost. Higher-income students had the opportunity to prepay and opt out of the repayment program, leaving the rest of the group behind to collectively pay on their own. This clause in the contracts' terms undermined the nature of the program's group repayment system (Levin, 2018). In addition, Yale's ISA program did not include many stipulations that are major features of modern ISA contracts. For instance, most modern ISAs feature repayment caps that release students from the agreement as soon as a certain percentage of tuition has been repaid; some universities have a repayment cap as low as 100\% of tuition, while other universities, such as Purdue University, maintain a repayment cap of 250\% of tuition (Purdue Research Foundation, 2020). Another addition to modern ISA terms is minimum income thresholds a student earning less than a specified amount is not subject to payments; this stipulation serves to protect students whose income is so low that repayments would compete with everyday purchases, such as food and housing. Lastly, unlike Yale, universities supporting modern ISA programs have instituted robust transparency policies so that students can understand the difference between traditional debt and an ISA before committing to either option. Because of the lack of protection for lower- and middle-income students, Yale's ISA program was eventually dismantled, and ISAs were viewed as a failed attempt at revolutionizing the affordability of higher education.

In recent years, ISAs have returned to the forefront of innovative strategies to open universities to middle-income students, primarily at trade schools for computer science and some large state research institutions. Trade schools for computer science have a recognized stability of job placement and income levels for graduates, which reduces the inherent risk of an ISA, including student unemployment and 
volatile income levels. The future income and job placement statistics have a lower variance, which facilitates the development of a more accurate forecast for financial planners. In addition, the overall cost of attendance for trade schools is significantly lower than other post-secondary education programs, and entry-level positions for computer science graduates pay relatively high salaries compared to other roles. With a lower cost of attendance and a high starting salary, computer science students at trade schools are prime candidates for ISAs (Eden, Domanico, Cooper, \& Bair, 2019).

Purdue University launched "Back a Boiler," their version of an ISA program, in 2016, making the university the first major state research institution to engage in the innovative funding strategy (Purdue News Service, 2018). The Purdue Research Foundation (PRF), a private, nonprofit foundation that supports the university by managing and licensing the institution's intellectual property, accepting gifts, administering trusts, and acquiring real estate, oversees the Back a Boiler program (About PRF 2020). Before the program launch, PRF raised approximately $\$ 16.5$ million to cover costs involved with initiating ISAs. Several different investors supported the initiative, "including [seven] institutional investors, one multi-strategy hedge fund, one family office, and five individual investors" (Purdue News Service, 2018). In its first year, the contracts were available to junior and senior students of any major. After a successful first year, the program extended to sophomore students. Contract terms vary by major at Purdue; for instance, rates will be different based on a student's major and the remaining payment balance after grants and scholarships. As seen in the figure below, fields of study that are in high demand, such as computer science, have lower fixed rates due to the higher probability of placement in a high-paying position after graduation. On the other hand, liberal arts and education majors typically receive higher fixed rates. Students do not begin making repayments to the university until six months have passed after graduation and the student is earning over $\$ 20,000$ per year (Purdue Research Foundation, 2020).

Figure 1: Back a Boiler Program Fixed ISA Rates and Terms by Major (Wharton, 2019)

Major Decision
Estimated payment schedule for a \$10,000 income-share agreement made through Purdue University in a
student's senior year, by major
Major




\section{Income Share Agreement Calculations}

Unlike traditional student loans, ISAs provide many benefits to students and alleviate concerns of the mounting debt crisis. While some traditional loans may require that payments begin before graduation, ISAs will never require payments to begin until post-graduation and after a student has secured a stable income exceeding $\$ 20,000$. Another benefit of payment calculations is the fixed rate tied to income; in the place of loan interest, ISA payments grow as income grows, which prevents payments from exceeding manageable levels. Traditional debt mandates that students carry the principal balance until all repayments have been made; on the other hand, ISAs have no principal amount, which creates variability in total repayment, possibly to the student's benefit. The total repayment under an ISA may or may not equal the total cost of a student's education.

The major incentive for students to participate in these agreements stems from the fact that their total repayment might be less than if they paid tuition out of pocket. Loan payment models are often overly complicated with variable interest rates and deferral options. ISA contracts, however, offer a simple, understandable payment model based on a fixed rate. If a student's future income greatly exceeds the average predictions, he or she will likely repay an amount greater than total cost of education, which amounts to a gain for the university. However, if a student's future income falls short of the projections, the total cost of education may not be recouped, representing a loss to the university. As shown in Figure 2, this potential for gains and losses emulates the nature of equity investments with both upside and downside risk, which incentivizes investors (the universities) to maximize the value of investment (the income level of college graduates) (Eden, Domanico, Cooper, \& Bair, 2019). Another incentive for students is that ISA contracts typically operate under a shorter time period than traditional loans, which gives greater financial liberty to college graduates later in life, when other costs, such as child care, real estate investments, and other expenses dominate personal budgeting (Zaber \& Edwards, 2019). While the concentration of repayment may be a benefit in some ways, this concentration may also prevent students from saving or investing money early in their careers, which could become a major disadvantage during their later lives. 
Figure 2: Scenario Analysis of Traditional Student Loans vs. ISAs (Eden, Domanico, Cooper, \& Bair, 2019)

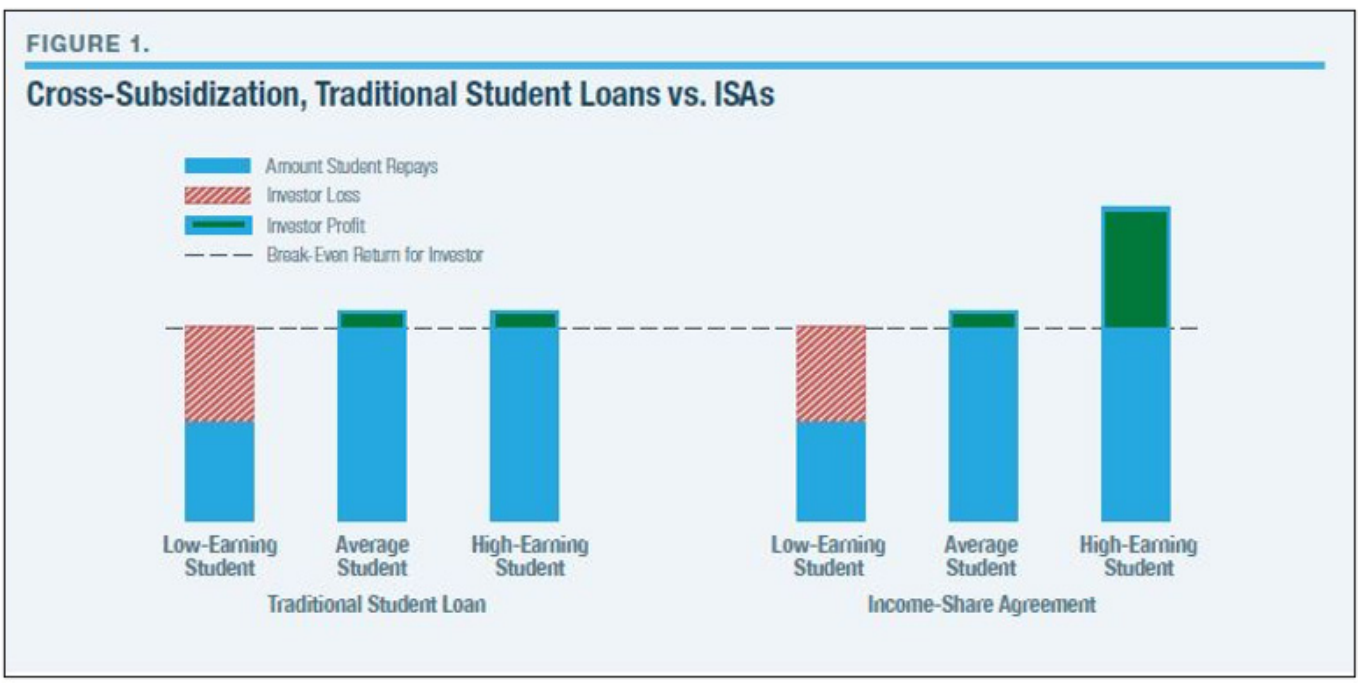

A significant distinction must be made between taxpayer-subsidized federal loans and higher-interest private loans or federal parent PLUS loans. Taxpayer-subsidized federal loans represent an inherently less risky financial instrument, which allows for artificially lowered interest rates; these debt instruments should, in most circumstances, offer an advantage to students over ISAs in terms of total amount repaid. Federal parent PLUS loans are secondary sources of federal financial aid, which are offered to parents of undergraduate students to cover the remainder of any unpaid costs associated with higher education (PLUS Loans 2020). Contrary to basic federal student loans, higher interest private loans and federal parent PLUS loans that are accountable for the mounting student debt crisis are often a worse engagement for students based on high interest rates and accumulation of interest regardless of a college graduate's income level or employment status.

\section{Free Market Implications and Adverse Selection Bias}

Based on free market assumptions, students deciding between assuming student debt or signing an income share agreement will select their funding source depending on their future prospects. A student who believes his or her job placement prospects are high and income prospects are positive will almost always self-select toward traditional student loans, according to basic logic; these students with more positive prospects will likely have a higher income and will, thus, likely repay a higher amount than the cost of tuition. Therefore, selecting traditional student loans will provide a more cost-effective opportunity. On the other hand, students with negative expectations for their future employment and income status will likely prefer to select the ISA because the amount they will repay may likely amount to less than the total remaining cost of tuition. Unfortunately, this free market assumption skews the population demographic toward students who will be unable to repay the full amount of tuition, which should increase rates and term lengths of ISAs in order to maintain profitability - an amendment that reduces the sustainability and equity-focus of the funding strategy. 
As Purdue University launched its own ISA program, Back a Boiler, the university had its concerns about adverse selection and skewed demographics in program participants. In 2018, graduate student Kevin Mumford authored a research article analyzing the decision process for students as they weighed ISAs and traditional student debt. Based on two years of historical data and surveys from students both participating in the ISA program and not participating, he found that adverse selection was surprisingly not intrusive to the program. Future prospects for students were not statistically correlated to a student's ultimate decision; similarly, student success (in terms of GPA and SAT scores) was also a nonfactor (Mumford, 2020).

One of Mumford's key findings was that students with positive expectations view ISAs as a strategy to reduce risk and hedge losses. Functioning as insurance policies, ISAs become tools for forwardthinking students. If a student believes that he or she will perform well in job placement and receive a high income, that student is also likely to be more risk averse in order to protect the earnings he or she is bringing in (Mumford, 2020).

However, Mumford offered strong cautions on the application of his findings to other universities' ISA programs. The lack of substantial adverse selection within the Back a Boiler program is largely due to two major stipulations: eligibility being limited to sophomores, juniors, and seniors as well as the varying rate structures based on student major and year in school. Some ISA programs are fully committed to increasing accessibility of higher education and will open eligibility to freshmen students, who have a higher likelihood of changing majors, which can impact future job placement and income level. Also, a program with a single repayment rate will incentivize students to choose a major or job with lower income projections; free market theory would likely become a dominant force in a student's decision-making process (Mumford, 2020).

\section{Donor vs. Institution-Based Funds}

In a donor-based ISA fund, education equity investments take on a form much more similar to that of stocks on a financial market. A personal investor will invest specifically in a student, signing the agreement personally. A similar alternative is to have privately-managed funds sign agreements with students, similar to how private student loans are issued. The downside of a third-party organization or individual investing directly in a student's education is the elimination of the shared value proposition with the university. Third parties do not have a direct impact on the education or job placement of students, which inherently makes the contracts riskier for investors because they have no ability to elevate potential of job placement. In addition, students do not receive the incremental support in the job search, which may lead to more difficulty in making repayments in future years.

Universities that directly fund ISA programs, alternatively, are incentivized to provide a higher quality education and higher-paying job placements to students. Additionally, these universities are positioned to actually impact students' career placement to garner a shared benefit for both parties under the contract. This direct involvement by universities in ISA management reduces economic risk by improving the probability of job placement via leverage of institutional resources, such as career centers and professional development centers. 


\section{Risks of Income Share Agreements}

Because ISA programs have only been fully integrated into higher education financing within the past five years, no concrete data exists to prove their long-term sustainability and effectiveness. With repayments occurring over the course of ten or more years, most actual repayments to date are only in the first few years of activity. Students graduating and beginning the fulfillment of their repayments has begun only three to four years ago. The limited data that is available will not be able to accurately forecast the financial viability of the program due to the growth rate of students' income; assuming that promotions, shifting to new careers for higher salaries or wages, and salary raises are common events throughout the first ten years of a college graduate's professional career, income levels will be significantly higher during year ten compared to soon after graduation. Thus, the majority of repayments (as a percentage of total tuition) will occur in the later years of contract's term. Within the next decade, more substantial data will be available for researchers to gain a full understanding of the efficacy of ISAs. Until that point, all models and pilots must be created under theoretical forecasting, which could greatly vary from actual results, contributing to an increased risk to institutions who sponsor these programs (Wharton, 2019).

Because of the novelty of these agreements, government officials have not created regulations to guarantee the enforceability, consumer protection standards, and other policies that heavily influence the implementation of ISA programs (Zaber \& Edwards, 2019). General law allows these contracts to be enforceable, but more detailed policies would reduce ambiguities within educational equity investments, resulting in a more secure system for institutions. On the other hand, consumer protection standards are not directly tied to the ISA industry, which opens many opportunities for institutions to take advantage of students in the fine print of contracts. Abuse of power is the source of many critics' reviews. Although modern ISA programs often have a maximum repayment ceiling (such as Purdue's 2.5x cost stipulation) and a minimum income to qualify for enforced repayments (such as Purdue's $\$ 20,000$ policy) among other student protections, these standards are not written into law. A university could theoretically draft fine print in contracts to push the majority of risk back on students (Wharton, 2019).

Lastly, a more intangible risk is the pressure that students may experience to pursue a higher-paying career, as opposed to a more fulfilling career. Many students go to college with a strong passion for a certain study or cause. For instance, non-profit organizations attract substantial attention from current university students despite offering lower salaries and benefits. Universities engaged in ISA contracts would be more likely to steer students toward careers in banking or consulting over lower-paying careers, such as those in the non-profit sector. This pressure may lead to a negative sentiment between the student and the university, and could possibly tarnish the brand image of an institution. 


\section{Legality of Income Share Agreements}

Currently, there is limited regulation surrounding the ISA market. Although most ISA providers include terms specifying protections for students, no laws have been confirmed to solidify safeguards for those engaged in these agreements. Major legal limitations include a lack of regulation concerning maximum repayment amounts or periods, discharge statutes, and reporting requirements (Zaber \& Edwards, 2019).

\section{Congressional Interest}

Over the past decade, Congress has paid much attention to the rising popularity of ISAs, and has attempted to provide more clarity and regulation to the arena to better protect students and investors. Notably, Senators Todd Young (R-Ind.), Marco Rubio (R-Fla.), and Tom Cotton (R-Ark.) introduced the Investing for Student Success Act of 2017, which defined ISAs legally and solidified tax procedures surrounding the contracts (CRS, 2017). Similar to the previously mentioned legislation, other bills have been introduced in Congress without success. Despite challenges, many legislators are still joining the movement to advocate for these educational investment contracts; in July of 2019, Senators Todd Young (R-Ind.), Mark Warner (D-Va.), Marco Rubio (R-Fla.), and Chris Coons (D-Del.) introduced the bipartisan bill ISA Student Protection Act to improve contract terms for students (Gallagher, 2019). The proposed legislation includes a number of terms that bolster protection of both students and investors, including the following (Young, 2019):

- Individuals making less than 200\% of the Federal Poverty Level (\$24,980 in 2019) are exempt from making payments toward their ISA.

- ISA providers cannot make agreements with students that require payments higher than $20 \%$ of income for shorterterm contracts, with the cap decreasing to $7.5 \%$ for the longest contracts allowed (30 years).

- ISAs are dischargeable in bankruptcy.

- Funders must disclose to students how their monthly payments would compare under the ISA to payments on a private or federal loan for the same amount of money and number of payments.

- Applies federal consumer protection laws (i.e. Fair Credit Reporting Act, Fair Debt Collection Practices Act, Military Lending Act, Servicemembers Civil Relief Act, Equal Credit Opportunity Act) to ISAs.

- Gives the Consumer Financial Protection Bureau oversight authority over ISAs.

- Clarifies the tax treatment of ISA contributions for both funders and recipients. 
Based on the bipartisan support of this bill, Congress is likely to see this legislation move further than past ISA legislation attempts, even possibly being signed into law. However, as discussions continue, Senate Democrats, including Sen. Elizabeth Warren, have raised more concerns about the contracts becoming "predatory and dangerous for students" (Berman, 2019). According to studies conducted by Skopos Labs, this bill has a 3\% chance of becoming law as it is written currently; amendments may adapt the direction of the bill, and some provisions may be removed (GovTrack, 2019).

\section{Methodology}

\section{Data Collection}

To develop a model fit for TCU's environment and student population, historical employment data was drawn from Handshake, TGU's online job posting and event management system. All years of data (2014 to 2019) were utilized in this study in order to derive comprehensive correlations between TCU employment rates and national employment rates. Data was organized by year and major in order to highlight how many students of which specific majors experienced unemployment during certain periods of time. Students graduating in May and December of the same academic year were grouped together to generate one year's unemployment rate. (For instance, unemployed graduates in the December Class of 2013 were included in the statistics for 2014 unemployment along with the May Class of 2014.) The Neeley School of Business was selected as the most fit academic unit for an ISA pilot program due to its built-out reporting of career outcomes and consistent job placement history. Therefore, only figures from this school were included in TCU unemployment data.

As a benchmark, national unemployment data was drawn from the U.S. Bureau of Labor Statistics website. Annual rates for unemployment were drawn from the government website for comparison to annual rates computed from TGU unemployment data. These annual national unemployment rates were taken from 2014 to 2019 in order to compare directly to the computed annual unemployment rates of TCU departments of study.

In order to forecast graduate income levels along the ten-year time horizon of a typical ISA, income growth rates were a necessary component in the calculation of repayments. During the spring of 2020, TCU Career Services studied the income growth rates of graduates, but data had not been finalized prior to this study. As a proxy, income growth data from the UT Austin McCombs School of Business was used for each major (BBA Career Management, 2019). Income levels at the one-, five-, and ten-year increments were reported by major. From these income levels, compound annual growth rates for each major were derived to use in subsequent repayment calculations.

\section{Assumptions}

In a realistic ISA program, students have the opportunity to take out an amount of funding from a preset range (often between $\$ 5,000$ and $\$ 20,000$ per year). The standard contract amount varies from institution to institution, but most universities observe $\$ 8,000$ to $\$ 10,000$ as the typical contract amount (Vemo Education, 2020). Based on the mathematical proportionality of repayment calculations, using a 
single contract amount simplifies the model while maintaining forecast integrity; therefore, repayment rates are based on ISA contracts for $\$ 10,000$.

Purdue University's Back a Boiler program features an online comparison tool that provides holistic data and projected outcomes for all financial aid tools (private loans, PLUS loans, and ISAs) to facilitate decision making for students (Purdue Research Foundation, 2020). Repayment rates for the TCU pilot program were initially drawn from this website to provide baseline estimates of TCU figures. Purdue offers specific interest rates for each major, which provides a more tailored but complex model of repayments. In order to minimize confusion and simplify modeling, most universities offer three interest rates and bucket majors into either high, medium, or low interest rates. After testing Purdue's rate structure on TCU student data, repayment rates were slightly adjusted to better fit TCU's pilot program. During this adjustment, rates were combined into three major categories, producing the final rate structure illustrated in Figure 3.

Figure 3: Repayment Rate Structure of Texas Christian University's Pilot ISA Program

\begin{tabular}{lr}
\hline \multicolumn{2}{c}{ Repayment Rates } \\
\hline Accounting & $3.39 \%$ \\
Business Information Systems & $3.39 \%$ \\
Entrepreneurship and Innovation & $3.39 \%$ \\
Finance & $3.31 \%$ \\
Finance with a Real Estate Concentration & $3.39 \%$ \\
Managing People and Organizations & $3.89 \%$ \\
Marketing & $3.89 \%$ \\
Supply Chain Management & $3.39 \%$
\end{tabular}

ISA programs are commonly grouped into three categories: breakeven, evergreen, and growth. Breakeven programs have repayment caps of 1.0x and often allow losses for the sake of widening the door of opportunity to attract students and increase enrollment. Evergreen programs have repayment caps of $1.2 x$ to $1.7 x$. Most programs fall into this category and do not significantly increase incremental revenues for universities (considering the cost of program management). Growth programs have repayment caps greater than $1.7 x$ but can become predatory for students. Higher repayment caps often attract scrutiny for scalping graduates by charging due to unnecessarily high paybacks. Purdue's repayment cap of $2.5 \mathrm{x}$ aims to add to the university bottom line, but in order to increase opportunity at TCU, an evergreen program would be the best target. In the first years, the program should maintain a higher repayment cap to guarantee sustainability. Therefore, the pilot's repayment cap was settled at 1.8x. During a future expansion of the program, the repayment cap could be lowered after analyzing reports on program success to date.

Income thresholds serve to protect students with low incomes, removing the repayment obligation if income levels fall below a certain value. This stipulation serves to guarantee that students are able to 
provide essential needs, such as food and shelter, for themselves and any dependents. Purdue's income threshold is $\$ 20,000$, which is a reasonable level to ensure student protection. An income threshold of $\$ 20,000$ would also have minimal impact on Neeley School of Business graduates, given their typical starting salary figures.

TGU, aiming to reinforce the sustainability of the university, has demonstrated risk-averse characteristics in financial proceedings, which encourages the use of a higher discount rate for net present value calculations within the pilot ISA program model. This project specifically appears to be risky in nature, given that TCU has no previous experience in the ISA space. Both of these statements support a higher discount rate (perhaps 15\%). However, with the greater number of institutions launching these programs around the nation, more data will be available to help TCU consider whether it should launch its pilot. Therefore, the final discount rate was lowered to $11 \%$.

During the course of an ISA's repayment window, some students may experience a "zero-payment year." In a realistic ISA program, these zero-payment years initiate a pause on repayments and extend the life of the repayment window until the student regains income stability. The number of repayment window extensions is typically regulated to a set number of months, commonly 60 months. Some factors that can cause a zero-payment year include, but are not limited to: returning to school for a master's or doctorate degree, taking time off from work to start a family, or experiencing physically-incapacitating medical conditions. It is important to note that zero-payment years do not include years that students are unemployed. Within the pilot ISA program for the Neeley School of Business, an assumed 5\% of students will be in zero-payment years at any point in time, and the model allows for independent $5 \%$ probabilities in each year of the ISA repayment window. Rather than incorporating an extension or pausing factor as in realistic models, model parameters were simplified by eliminating this extension and decreasing the zero-payment year probability overall.

Lastly, program prerequisites are often stricter for initial pilot programs than in fully-developed, university-wide ISA programs (Vemo Education, 2020). In order to control the environment and protect the university in the endeavor, limitations to the scope of the program will be constructed. First, the pilot should only accept applicants who have been admitted to the Neeley School of Business (rising juniors and seniors); pre-business students should not be eligible to participate in an ISA. First- and second-year students maintain a higher likelihood to change majors after signing a contract based on a repayment rate, which poses significant risk to the institution. For instance, if a pre-business student intending on majoring in finance agreed to a contract based on the $3.31 \%$ income share percentage rate later changed majors to marketing, the repayments will likely be lower than anticipated. A potential solution for the expanded program in phase two or three of the expansion may include a specific repayment rate for pre-business majors. Second, mutual consent will drive participation in the pilot ISA program; students will apply to initiate an ISA with the university, and the university's financial aid staff will select students based on GPA, among other measurable factors. This application process will allow the pilot program to contain students who both could benefit financially from participation as well as have positive prospects on future employment and professional success. 


\section{Analysis Techniques}

Stochastic variables in the model include the national unemployment rate, the TCU unemployment rate (specific to each major), and an income growth rate multiplier. These variables were correlated in order to develop a multivariate distribution of realistic combinations. Basic correlations were computed for the national unemployment rate and the unemployment rate of each major within the Neeley School of Business. The correlation for the unemployment rates and the income growth rate multiplier was deduced based on economic logic. As unemployment increases, promotions and raises will become less common in the work force, which suggests a negative correlation. These movements are not guaranteed in many industries for business school graduates, such as finance, where economic downturns may generate greater opportunity for business school graduates. Therefore, a -0.5 correlation was assigned to unemployment and the income growth rate multiplier to indicate probable, but not guaranteed, opposite movement of these variables. The Gaussian copula organized these correlated variables into the multivariate distribution. Notably, the Gaussian copula underestimates downside risk by not accounting for the exaggerated and compounding nature of negative scenarios. Therefore, further sensitivity analyses were included in the model to understand downside risk.

Each scenario generated by the correlated stochastic variable sets represented one possible outcome from an ISA. Using loop VBA code, 10,000 scenario NPVs were drawn for each major to create a statistically significant population of expected outcomes. Correlated variables ensured that each scenario incorporated realistic possibilities, eliminating randomly occurring scenarios. Statistics, including mean, median, standard deviation, maximum, and minimum, were run based on the generated outcomes. In addition, the probability of a negative NPV scenario for an ISA contract in each major was calculated in order to predict overall risk.

Additional Monte Carlo simulations were run to generate sensitivity analyses based on the nonstochastic variables: the discount rate, the repayment cap, and the repayment rates. Discount rates were changed in two percent increments both positively and negatively to illustrate outcomes based on discount rates ranging from 7\% to 15\%. Repayment caps were modified by $35 \%$ increments both positively and negatively to express outcomes based on repayment caps ranging from $110 \%$ to $250 \%$. Each major was tested using the repayment rates for each primary bucket in the pilot program rate structure. Next, tests for each major were run using repayment rates $0.2 \%$ and $0.4 \%$ higher than the highest repayment rate in the program, and tests for each major were run using rates $0.2 \%$ and $0.4 \%$ lower than the lowest repayment rate in the program.

\section{Results}

Statistical analysis of Monte Carlo simulations determined that the NPV probability distributions were heavily skewed toward positive results. The mean NPV figures for ISA contracts within a pilot program in the Neeley School of Business ranged from $\$ 3,132.16$ to $\$ 6,480.27$. The Finance with a Real Estate Concentration field of study returned the lowest average and median NPV, while the Finance field of study returned the highest average and NPV. The Business Information Systems field of study returned the highest median NPV at $\$ 6,780.47$. Standard deviations for all majors ranged from 
$\$ 1,311.03$ to $\$ 1,613.28$, making distributions relatively similar in spread. The maximum repayment NPVs were noted in both the fields of Finance and Managing People and Organizations at \$8,000.00. The minimum repayment NPV was expressed as $(\$ 5,241.64)$ in the Supply Chain Management field of study.

Profitability indices were calculated for each major's typical ISA contract. The $\$ 10,000$ amount covered by the ISA served as the initial outlay for the profitability index calculation. Mean NPV of cash repayments divided by this initial outlay determined the profitability index for each major's typical ISA contract. These profitability results directly correlate to the results of mean NPV tests. Therefore, the highest profitability index value remains with ISA contracts written for students studying Finance, and the lowest profitability index value remains with ISA contracts written for students studying Finance with a Real Estate Concentration. Full statistics are listed in Figure 4.

Figure 4: Monte Carlo Simulation Statistical Analysis Results

\begin{tabular}{|c|c|c|c|c|c|c|c|}
\hline \multicolumn{8}{|c|}{ Results } \\
\hline & Mean NPV & Median NPV & NP & Std. Dev. & Max NPV & Min NPV & Profitability Index \\
\hline Accounting & $\$ 4,279.71$ & $\$ 4,191.39$ & $\$$ & $1,378.18$ & $\$ 6,095.60$ & $\$(2,828.27)$ & 1.43 \\
\hline Business Information Systems & $\$ 5,968.61$ & $\$ 6,780.47$ & $\$$ & $1,333.92$ & $\$ 7,511.41$ & $\$(423.88)$ & 1.60 \\
\hline Entrepreneurship and Innovation & $\$ 3,863.02$ & $\$ 3,870.94$ & $\$$ & $1,396.40$ & $\$ 5,624.90$ & $\$(2,889.36)$ & 1.39 \\
\hline Finance & $\$ 6,480.27$ & $\$ 6,564.50$ & $\$$ & $1,595.85$ & $\$ 8,000.00$ & $\$(2,698.12)$ & 1.65 \\
\hline Finance with a Real Estate Concentration & $\$ 3,132.16$ & $\$ 3,109.17$ & $\$$ & $1,311.03$ & $\$ 4,866.76$ & $\$(3,134.98)$ & 1.31 \\
\hline Managing People and Organizations & $\$ 6,336.87$ & $\$ 6,319.57$ & $\$$ & $1,613.28$ & $\$ 8,000.00$ & $\$(1,593.31)$ & 1.63 \\
\hline Marketing & $\$ 4,239.29$ & $\$ 4,148.66$ & $\$$ & $1,319.20$ & $\$ 5,825.95$ & $\$(3,596.80)$ & 1.42 \\
\hline Supply Chain Management & $\$ 3,482.53$ & $\$ 3,601.23$ & $\$$ & $1,470.78$ & $\$ 5,548.02$ & $\$(5,241.64)$ & 1.35 \\
\hline
\end{tabular}

Scenario analysis tests were performed to understand impacts using varying discount rates, repayment caps, and repayment rates. With lower discount rates, mean NPV values increased, and as discount rates increased, mean NPV values decreased. Notably, mean NPV values never decreased below zero, which illustrates that even in high discount rate environments, a pilot ISA program could still be an attractive project for Texas Christian University, albeit with more risk. Scenario analysis results investigating varying discount rates are illustrated in Figure 5. Bolded figures indicate average NPVs as calculated using original model assumptions.

Figure 5: Scenario Analysis of Varying Discount Rates

\begin{tabular}{|c|c|c|c|c|c|}
\hline \multicolumn{6}{|c|}{ Sensitivity Analysis: Discount Rate by Major } \\
\hline & $7 \%$ & $9 \%$ & $11 \%$ & $13 \%$ & $15 \%$ \\
\hline АCCT & $\$ 6,882.25$ & $\$ 5,641.46$ & $\$ 4,279.71$ & $\$ 2,981.60$ & $\$ 2,013.99$ \\
\hline BIS & $\$ 7,780.51$ & $\$ 7,199.21$ & $\$ 5,968.61$ & $\$ 4,558.30$ & $\$ 3,419.33$ \\
\hline E\&I & $\$ 6,485.16$ & $\$ 5,192.00$ & $\$ 3,863.02$ & $\$ 2,555.61$ & $\$ 1,601.53$ \\
\hline FINA & $\$ 7,809.72$ & $\$ 7,345.36$ & $\$ 6,480.27$ & $\$ 5,113.22$ & $\$ 3,747.31$ \\
\hline FINA + RE & $\$ 5,944.21$ & $\$ 4,427.88$ & $\$ 3,1$ & $\$ 1,976.49$ & $\$ 1,007.27$ \\
\hline MPO & $\$ 7,709.77$ & $\$ 7,198.83$ & $\$ 6,336.87$ & $\$ 4,835.19$ & $\$ 3,578.40$ \\
\hline MKTG & $\$ 6,681.82$ & $\$ 5,493.75$ & $\$ 4,239.29$ & $\$ 2,860.36$ & $\$ 1,715.92$ \\
\hline SCM & $\$ 6,285.63$ & $\$ 4,820.33$ & $\$ 3,482.53$ & $\$ 2,328.95$ & $\$ 1,270.90$ \\
\hline
\end{tabular}


To investigate the impact of different types of ISA program design, a scenario analysis involving varying repayment caps was developed. Lowest repayment caps in the scenario analysis mimic a breakeven program design. Highest repayment caps mimic a growth program design, similar to that of Purdue University's Back a Boiler ISA program. Lowering repayment caps limits the mean NPV drastically by generating a majority of repayment scenarios reaching the repayment ceiling. As noted in Figure 6, average NPVs for most majors' ISA contracts settled relatively close to $\$ 1,000$ for a $1.1 \mathrm{x}$ repayment cap design and $\$ 4,500$ for a $1.45 x$ repayment cap design. Above a 1.8x repayment cap design, there was no significant difference in average NPV figures. Maximum NPVs were higher in some majors' ISA contracts, but overall impact to mean values was minimal. In a high repayment cap program, TCU would capture substantially higher amounts from an extremely small subset of students, which explains the minimal impact to average NPV as repayment caps are increased. This trend supports the conclusion that evergreen repayment caps are not only less predatory, but they are also nearly equally financially sustainable to growth repayment caps.

Figure 6: Scenario Analysis of Varying Repayment Caps

\begin{tabular}{|l|cc|c|ccc|}
\hline \multicolumn{7}{c}{ Sensitivity Analysis: Repayment Cap by Major } \\
\hline & $\mathbf{1 1 0 \%}$ & $\mathbf{1 4 5 \%}$ & $\mathbf{1 8 0} \%$ & $\mathbf{2 1 5 \%}$ & $\mathbf{2 5 0} \%$ \\
\hline ACCT & $\$ 976.95$ & $\$ 3,822.56$ & $\mathbf{\$ 4 , 2 7 9 . 7 1}$ & $\$ 4,302.12$ & $\$ 4,218.93$ \\
BIS & $\$ 994.38$ & $\$ 4,321.15$ & $\mathbf{\$ 5 , 9 6 8 . 6 1}$ & $\$ 5,961.63$ & $\$ 5,952.06$ \\
E\&I & $\$ 961.68$ & $\$ 3,488.52$ & $\mathbf{\$ 3 , 8 6 3 . 0 2}$ & $\$ 3,796.97$ & $\$ 3,797.06$ \\
FINA & $\$ 996.00$ & $\$ 4,384.86$ & $\mathbf{\$ 6 , 4 8 0 . 2 7}$ & $\$ 6,509.01$ & $\$ 6,589.93$ \\
FINA + RE & $\$ 934.71$ & $\$ 3,175.55$ & $\mathbf{\$ 3 , 1 3 2 . 1 6}$ & $\$ 3,056.80$ & $\$ 3,168.98$ \\
MPO & $\$ 992.74$ & $\$ 4,291.15$ & $\mathbf{\$ 6 , 3 3 6 . 8 7}$ & $\$ 6,178.96$ & $\$ 6,203.43$ \\
MKTG & $\$ 969.17$ & $\$ 3,690.30$ & $\mathbf{\$ 4 , 2 3 9 . 2 9}$ & $\$ 4,044.49$ & $\$ 3,950.85$ \\
SCM & $\$ 939.05$ & $\$ 3,355.69$ & $\mathbf{\$ 3 , 4 8 2 . 5 3}$ & $\$ 3,524.00$ & $\$ 3,388.95$
\end{tabular}

The scenario analysis test for varying repayment rates utilized rates both above and below standard buckets for Neeley School of Business ISA contracts. Figure 7 illustrates results of changing repayment rates for each major's mean NPV for a typical ISA contract. This test proves that even slight rate changes (in this case, changes of $0.2 \%$ ) have the potential to majorly impact mean NPV values. At higher repayment rates, changes observed were less extreme as compared to changes at lower interest rates due to the repayment cap in place at $1.8 x$. As repayment scenarios increased with higher repayment rates, many observations maximized allowable repayments. Even when repayment rates were decreased, contracts written for students in Finance still maintained high mean NPV figures. Other majors experienced similar success while repayment rates declined, which provided a future opportunity to lower repayment rates as program data offers concrete insights on performance. 
Figure 7: Scenario Analysis of Varying Repayment Rates

\begin{tabular}{|c|c|c|c|c|c|c|c|}
\hline \multicolumn{8}{|c|}{ Sensitivity Analysis: Repayment Rate by Major } \\
\hline & $2.91 \%$ & $3.11 \%$ & $3.31 \%$ & $3.39 \%$ & $3.89 \%$ & $4.09 \%$ & $4.29 \%$ \\
\hline ACCT & $\$ 2,161.42$ & $\$ 3,062.00$ & $\$ 3,917.15$ & $\$ 4,279.71$ & $\$ 6,250.67$ & $\$ 6,873.97$ & $\$ 7,330.74$ \\
\hline BIS & $\$ 3,608.96$ & $\$ 4,621.22$ & $\$ 5,602.89$ & $\$ 5,968.61$ & $\$ 7,448.41$ & $\$ 7,712.20$ & $\$ 7,856.70$ \\
\hline E\&I & $\$ 1,846.30$ & $\$ 2,659.32$ & $\$ 3,450.36$ & $\$ 3,863.02$ & $\$ 5,862.26$ & $\$ 6,474.84$ & $\$ 6,962.67$ \\
\hline FINA & $\$ 4,613.29$ & $\$ 5,573.13$ & $\$ 6,480.27$ & $\$ 6,679.59$ & $\$ 7,592.44$ & $\$ 7,833.75$ & $\$ 7,891.02$ \\
\hline FINA + RE & $\$ 1,231.91$ & $\$ 2,010.08$ & $\$ 2,765.97$ & $\$ 3,132.16$ & $\$ 5,152.48$ & $\$ 5,877.16$ & $\$ 6,548.08$ \\
\hline MPO & $\$ 2,146.04$ & $\$ 2,931.07$ & $\$ 3,753.67$ & $\$ 4,072.13$ & $\$ 6,3$ & $\$ 6,654.36$ & $\$ 7,201.62$ \\
\hline MKTG & $\$ 491.34$ & $\$ 1,235.99$ & $\$ 1,950.83$ & $\$ 2,145.23$ & $\$ 4,239.29$ & $\$ 4,690.15$ & $\$ 5,467.48$ \\
\hline SCM & $\$ 1,562.57$ & $\$ 2,435.32$ & $\$ 3,154.31$ & $\$ 3,482.53$ & $\$ 5,414.98$ & $\$ 6,219.64$ & $\$ 6,708.70$ \\
\hline
\end{tabular}

From the Monte Carlo simulations, histograms formatted with cubic spline smoothing functions were generated. These histograms approximate the probability distribution functions for each major's ISA contract NPV scenarios. These distributions give more perspective on which scenarios are most likely to occur in a realistic implementation of the model. Each histogram demonstrates the overwhelmingly high likelihood of a positive NPV ISA contract for any major within the Neeley School of Business. The distributions are right-modal and skewed left due to the repayment cap curtailing the highest repayment scenarios at $\$ 8,000$. The low amplitude of frequency values for negative NPV contracts illustrates the low probability for an ISA contract in that major to be unprofitable. Figure 8 provides full histogram outputs for each major's ISA contract Monte Carlo simulation results. 
Figure 8: Histogram Outputs from Monte Carlo Simulation
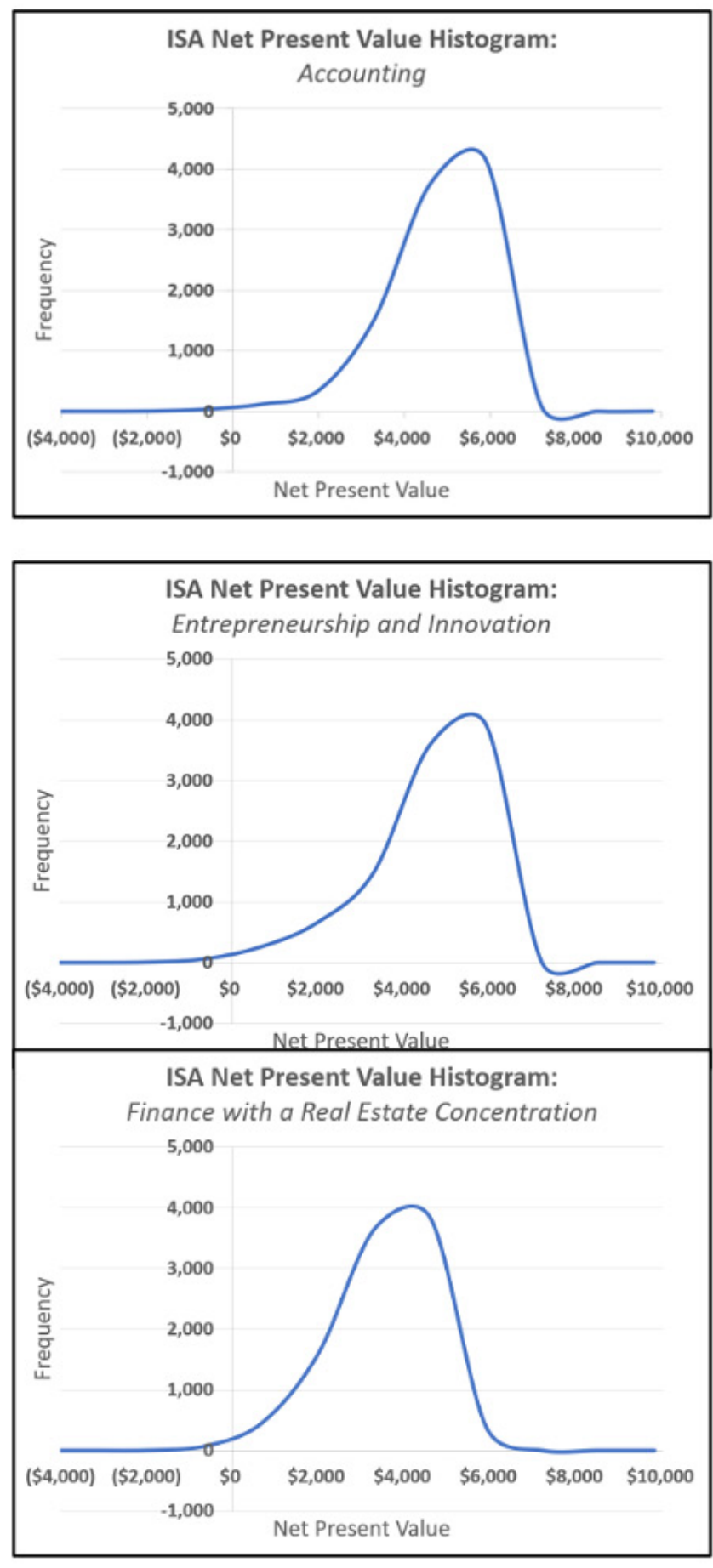
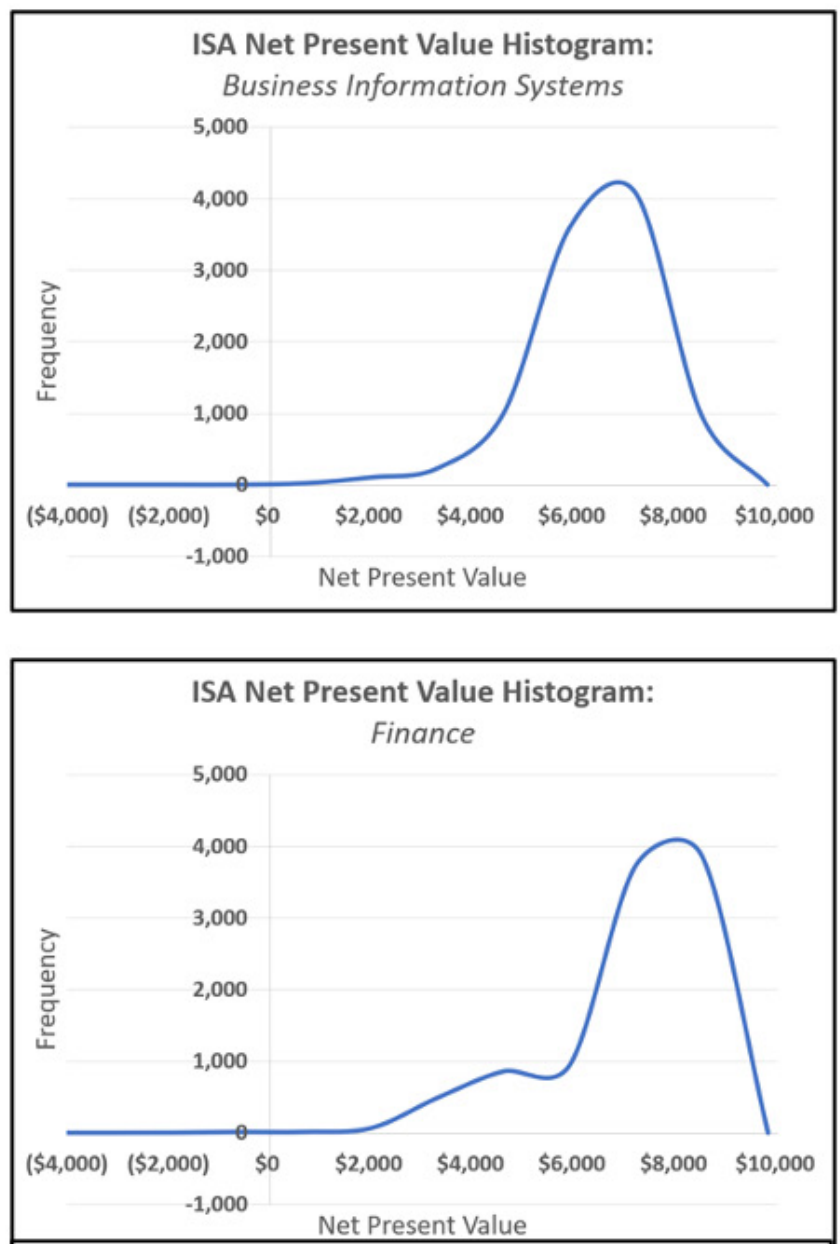

ISA Net Present Value Histogram: Managing People and Organizations 5,000

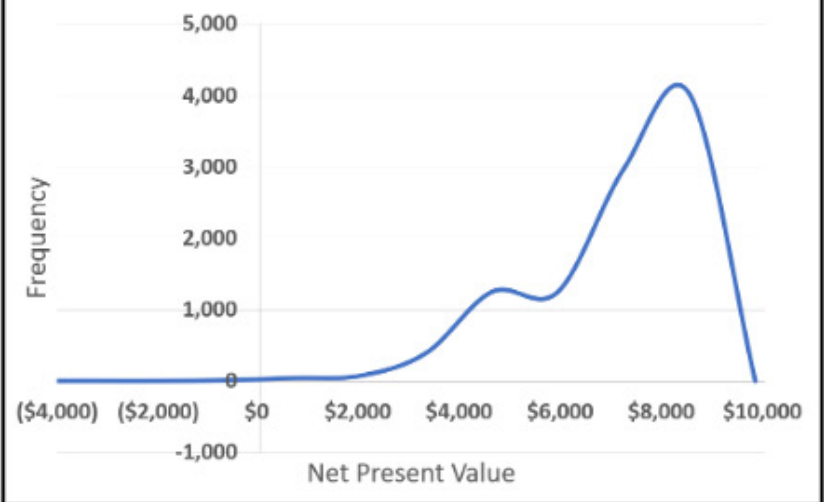


Figure 8: Histogram Outputs from Monte Carlo Simulation (continued)
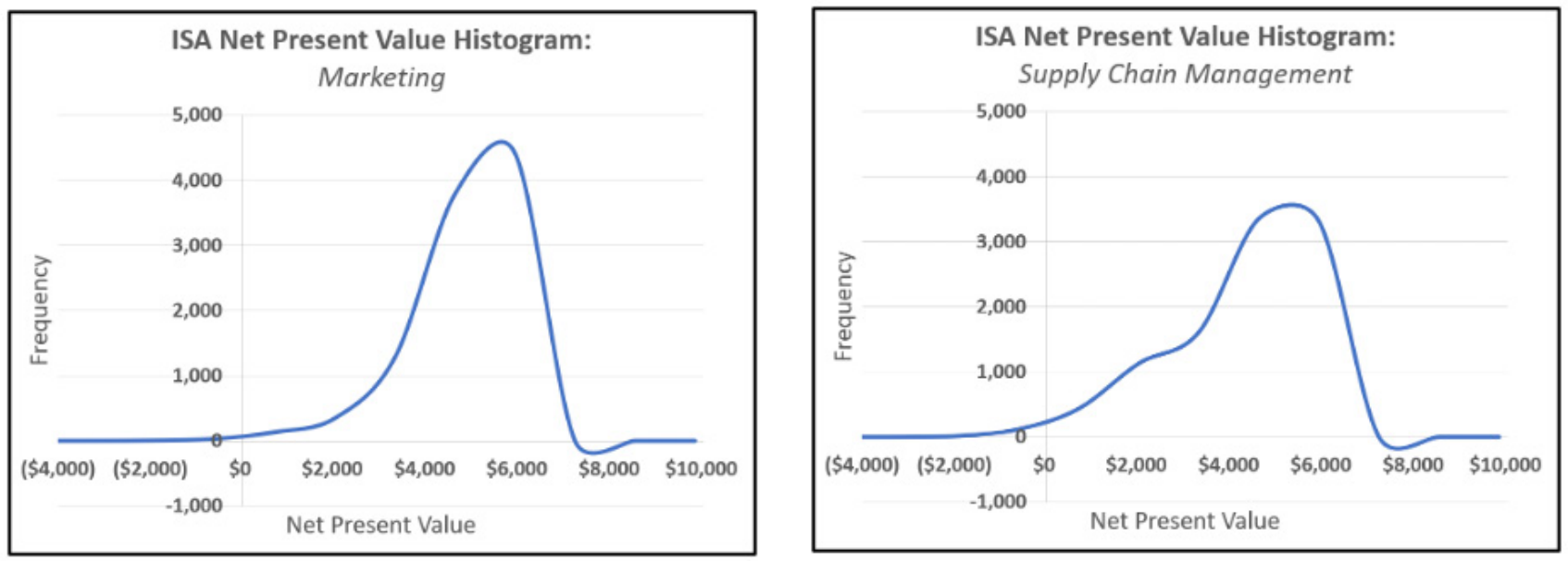

As seen in the histogram outputs from Figure 8, the probability of negative NPV ISA contracts is low for every major within the Neeley School of Business, based on the pilot program parameters. The highest probability to witness an actual negative NPV ISA contract is in the field of Finance with a concentration in Real Estate, with a probability of $2.63 \%$. The lowest probability of generating a negative NPV ISA contract in the Business Information field of study is $0.03 \%$. Figure 9 illustrates the probability for an ISA contract to return a negative NPV based on the Monte Carlo simulation of original assumptions.

Figure 9: Probability for an ISA Contract to Return a Negative Net Present Value

\section{Probability of Returning a Negative NPV ISA Contract}

\begin{tabular}{l|l} 
Accounting & $0.65 \%$ \\
\hline Business Information Systems & $0.03 \%$ \\
\hline Entrepreneurship and Innovation & $0.97 \%$ \\
\hline Finance & $0.14 \%$ \\
\hline Finance with a Real Estate Concentration & $2.63 \%$ \\
Managing People and Organizations & $0.10 \%$ \\
Marketing & $0.58 \%$ \\
Supply Chain Management & $1.77 \%$
\end{tabular}

To better understand the downside risk of an ISA program at TGU, value at risk and expected shortfall statistics were computed for each field of study. The value at risk represents the expected outcome if an ISA contract occurs with a specific probability on the left tail of the distribution. The expected shortfall statistic represents the average expected outcome if an ISA contract occurs with a specific probability or worse on the left tail of the distribution. The expected shortfall calculation 
accounts for the existence of outliers within the data in order to understand all potential outcomes of a contract. Statistics were calculated at both the $5 \%$ and $10 \%$ probability levels in order to provide multiple cross-sections of risk analysis. Even in a negative scenario occurring with $5 \%$ probability, all fields of study maintain positive NPV contracts. When accounting for all events below 5\% probability in the expected shortfall statistic, two fields of study, Finance with a Real Estate Concentration indicate negative NPV contracts. Figure 10 illustrates advanced risk measures for ISA contracts by field of study based on original model assumptions.

Figure 10: Advanced Risk Measures for ISA Contracts by Field of Study

\begin{tabular}{|c|c|c|c|c|c|c|c|c|}
\hline \multicolumn{9}{|c|}{ Advanced Risk Measures } \\
\hline & \multicolumn{2}{|c|}{$\begin{array}{c}\text { Value at Risk } \\
(5 \%)\end{array}$} & \multicolumn{2}{|c|}{$\begin{array}{c}\text { Expected } \\
\text { Shortfall }(5 \%)\end{array}$} & \multicolumn{2}{|c|}{$\begin{array}{c}\text { Value at Risk } \\
(10 \%)\end{array}$} & \multicolumn{2}{|c|}{$\begin{array}{c}\text { Expected } \\
\text { Shortfall }(10 \%)\end{array}$} \\
\hline Accounting & $\$$ & $1,999.27$ & $\$$ & 786.28 & $\$$ & $2,363.58$ & $\$$ & $1,504.50$ \\
\hline Business Information Systems & $\$$ & $3,469.84$ & $\$$ & $2,625.32$ & $\$$ & $3,866.94$ & $\$$ & $3,142.96$ \\
\hline Entrepreneurship and Innovation & $\$$ & $1,133.21$ & $\$$ & 311.37 & $\$$ & $1,999.95$ & $\$$ & $1,035.40$ \\
\hline Finance & $\$$ & $3,057.37$ & $\$$ & $2,315.53$ & $\$$ & $4,397.21$ & $\$$ & $3,171.84$ \\
\hline Finance with a Real Estate Concentration & $\$$ & 463.57 & $\$$ & $(190.50)$ & $\$$ & $1,358.10$ & $\$$ & 475.67 \\
\hline Managing People and Organizations & $\$$ & $3,203.43$ & $\$$ & $2,187.64$ & $\$$ & $4,142.77$ & $\$$ & $3,048.58$ \\
\hline Marketing & $\$$ & $1,978.64$ & $\$$ & 892.42 & $\$$ & $2,326.88$ & $\$$ & $1,534.49$ \\
\hline Supply Chain Management & $\$$ & 600.74 & $\$$ & $(134.65)$ & $\$$ & $1,688.19$ & $\$$ & 508.32 \\
\hline
\end{tabular}

In all model results, Finance with a Real Estate Concentration and Supply Chain Management consistently report the lowest contract NPV figures as well as the highest probability of negative NPVs. Despite these findings, the downside risk of these contracts is minimal enough to mitigate the financial anxieties of the institution. If the university wishes to reduce the probability of negative events in these contracts, the repayment rates for these specific majors could be increased to a higher tier. However, with current assumptions and findings, these fields of study demonstrate robust potential to serve as sustainable contract programs without a repayment rate increase. Students and the general public may interpret such repayment rate increases as unnecessarily predatory. By increasing the number of students within a program, positive NPV contracts should outweigh negative NPV contracts similar to a portfolio of stocks with positive and negative returns balancing each other to develop a net positive return effect. Repayment rates for ISA contracts are analogous to dividend yields for stocks. By shifting perspectives from debt financing (with student loans) to equity financing (ISA contracts), basic portfolio theory can be applied to generate a flexible and sustainable ISA program at TCU. 


\section{Conclusion}

Income Share Agreements have been tested in many scenarios over past decades in order to solidify their theoretical foundation in becoming a mainstream alternative to debt financing in education. Their focus on equitable repayments and sustainable programs has created a promising argument for their presence at more institutions across the United States. Given the consistent results of this study that show positive net present values as well as low probability for negative net present values for all of the forecasted ISA contracts within TCU's Neeley School of Business, a pilot program has statistically significant validation to be implemented.

Due to COVID-19, universities across the nation are facing significant challenges, not only to maintain operations for current students but also to maintain stable enrollment numbers for future classes. The financial burden of the pandemic is forcing many college hopefuls to reconsider the value of costly private post-secondary education. In addition, after the cessation of in-person learning at most universities, students faced the difficult transition to moving home in the midst of a national emergency, abandoning belongings in different states for the sake of personal safety. This spontaneous migration home for students is expected to leave lasting impressions on future students as they consider their university of choice (Vemo Education, 2020).

For a private, four-year, not-for-profit institution like TGU, these future projections will likely pose major challenges to financial stability. With the cost of tuition consistently rising at approximately $4.9 \%$ each academic year, TCU is climbing the list of most expensive colleges in the United States, despite mounting financial pressures for families. Furthermore, the majority of TCU's student population comes from out of state, which will cause student selection trends biasing toward in-state schools to have a multiplied effect on the university. Certainly, some students from Texas, who may have chosen an outof-state college, will choose to remain in Texas next fall due to COVID-19, which could dampen the negative implications of these trends. However, overall forecasts present a challenging future ahead for TCU and similarly structured institutions.

Income Share Agreements may prove to be a powerful solution to some of the obstacles presented by the COVID-19 crisis, specifically in remediating financial burden on families. In order to retain students already present at the university who are experiencing financial hardship due to stock market downturn or unemployment, ISAs can be an alternative method to pass financial burdens to future periods while also limiting the risks of unemployment post-graduation. In these times of uncertain job markets, students will be hesitant to assume greater student debt for fear of not having an income at graduation to make interest payments. However, ISAs provide assurance for an education with limited downside risk in the case of unemployment post-graduation. This tool could be a master key to unlock opportunity in a period of economic instability in the country.

Second, as political figures discuss the affordability of higher education, many ideas center upon providing debt relief for students and graduates or even creating a system of free public higher education. Specifically, in the case that free higher education of any kind comes to fruition, private, notfor-profit institutions will not likely receive the same benefits from the government as public institutions. If students are deciding between a free education and a $\$ 60,000$ per year education, most will likely opt for the free opportunity. This scenario would render private universities, such as TCU, uncompetitive 
in the market and poised for failure. In order to maintain competitiveness in the market and prepare in advance of such policy changes, these types of institutions need to innovate in order to survive. Generating opportunity and financial access will likely maintain enrollment figures while bolstering retention rates. Preemptive action within financial aid programs is necessary to remain viable in an evolving industry, and the pilot ISA program projections from this study suggest this tool as a strong contender for innovative alternatives to current student challenges.

\section{Continued Research}

There are many areas of research that could further expand the findings and significance of this study. Continued investigation could emphasize the following topics:

- Shared value and stakeholder theory analysis of Income Share Agreements could provide interesting perspectives on the actual implications of these contracts on all parties involved. Once more years of data are available from other institutions, a study could comprehensively analyze the positive and negative consequences of this financial aid strategy.

- One concern of many ISA programs is moral hazard, in which students lose motivation to succeed academically and professionally once they are locked into the constraints of repayment rates and income thresholds. Theoretically speaking, a student could be incentivized to minimize his or her income in order to fall below the income threshold or at least minimize monthly repayments. Analyzing this psychological behavior could provide insight on predictive financial modeling and future forecasts for ISA programs.

- In a university-managed ISA program, career services staff may place an undue priority on placing students contracted under ISAs in higher paying industries or positions. This trend can be viewed positively and negatively to some extent, but most would argue that it aligns the interests of both university staff and students in emphasizing professional outcomes and overall student success. However, if a third-party organization manages the ISA program for the university, there is not a comparable alignment of priorities. Therefore, job outcomes, and therefore repayment figures, may be different based on the management of an ISA program. A comparative analysis of these types of programs may expose trends currently unknown.

- In order to tangibly further this case study, a university-wide model must be developed for TGU before expanding the program to include all majors and all students. This comprehensive case study of TGU should be more complex and detailed in order to best inform administrative decisions. 


\section{Appendix: Works Cited}

About Income Share Agreements (ISAs). (2020). Retrieved May 01, 2020, from https://incomeshareagreements.org/income-share-agreements-isas/

About PRF. (2020). Retrieved from https://prf.org/about/index.html

Adams, S. (2018). Mitch Daniels Is Making Purdue More Affordable And Upping Enrollment. Higher-Ed Purists Are Aghast. Forbes.Com, 1. Retrieved from http://search.ebscohost.com.ezproxy.tcu. edu/login.aspx? direct=true\&AuthType=cookie,ip, uid\&db=bth\&AN=131718318\&site=ehost-live

BBA Career Management. (2019). [2018-2019 Full Time Statistics for UT McCombs Undergraduates]. Unpublished raw data.

Berman, J. (2019, June 5). Elizabeth Warren criticizes letting students pay for college by selling a stake in their future earnings. Retrieved May 1, 2020, from https://www.marketwatch.com/story/elizabeth-warren-criticizes-letting-students-pay-for- college-by-selling-a-stake-in-their-future-earnings-2019-06-05

Cass, M. (2015). Purdue Seeks Partner For Income Share Agreements. Foundation \& Endowment Money Management, 8. Retrieved from http://lib.tcu.edu/PURL/EZproxy_link.asp?url=http:/ / search.ebscohost.com.ezproxy.tcu.edu/login.aspx?direct=true\&AuthType=cookie,ip,uid\&db=bth\&AN=109341097\&site=ehost-live

CRS. (2017, February 01). S.268 - 115th Congress (2017-2018): Investing in Student Success Act of 2017. Retrieved May 01, 2020, from https://www.congress.gov/bill/115th-congress/senate-bill/268

Eden, M., Domanico, R., Cooper, P., \& Bair, S. (2019, March 12). The Future of Income-Share Agreements. Retrieved from https://www.manhattan-institute.org/future-income-share-agreements-to-finance-higher-education

Gallagher, J. (2019, July 18). Bipartisan Income Share Agreement Legislation Introduced in the Senate. Retrieved May 01, 2020, from https://careerkarma.com/blog/bipartisan-isa-legislation-introduced-in-senate/

GovTrack.us. (2020). S. 2114 - 116th Congress: ISA Student Protection Act of 2019. Retrieved from https://www.govtrack.us/congress/bills/116/s2114

Income Share Agreements: A Solution to the Student Debt Crisis? (2019, July 17). Retrieved from https://publicpolicy.wharton.upenn.edu/live/news/3057-income-share-agreements-a-solution-tothe-student 
Institute for College Access \& Success. (February 22, 2019). Average cost for tuition and other fees at universities in the United States from 2000/01 to 2016/17 (in U.S. dollars)* [Graph]. In Statista. Retrieved October 04, 2019, from https://www.statista.com/statistics/238109/tuition-and-fees-inthe-us/

Levin, B. (2018, May 15). How Yale's 'Failed' Income Share Experiment Worked for Me. Retrieved from https://www.realcleareducation.com/articles/2018/05/15/how_yales_failed_income_share_experiment_worked_for_me_110277.html

Mumford, K. J. (2020, February). Student Selection into an Income Share Agreement [Scholarly project]. In Krannert School of Management. Retrieved from https://krannert.purdue.edu/faculty/kjmumfor/papers/ Mumford\%20Income\%20Share\%20Agreement\%20Selection.pdf

NCES. (November 30, 2018). Average tuition and fees compared to average student loan amount received in the United States 2017/18, by institution type (in U.S. dollars) [Graph]. In Statista. Retrieved October 04, 2019, from https://www.statista.com/statistics/237924/tuition-costs-vs-studentloans-in-the-us/

Neeley School of Business. (2020). [Fast Facts 2019-20, Neeley School of Business]. Unpublished raw data.

Pentis, A. (2020, March 13). 8 Universities That Offer Income-Share-Agreements. Retrieved from https://studentloanhero.com/featured/schools-bachelors-income-share-agreements/

PLUS Loans. (2020, February 01). Retrieved May 01, 2020, from https://studentaid.gov/understand-aid/types/loans/plus

Purdue News Service. (2018, December 4). Purdue Research Foundation raises $\$ 10.2$ million for Back a Boiler Income Share Agreement Fund II. Retrieved from https://www.purdue.edu/newsroom/ releases/2018/Q4/purdue-research-foundation-raises-10.2-million-for-back-a-boiler-income-shareagreement-fund-ii.html

Purdue Research Foundation. (2020). FAQ about Back a Boiler - ISA Fund. Retrieved from https:// www.purdue.edu/backaboiler/FAQ/index.html

US Department of Education. (October 19, 2018). Average annual cost to attend university in the United States, by institution type 2013-2019 (in U.S. dollars) [Graph]. In Statista. Retrieved October 04, 2019, from https://www.statista.com/statistics/235651/us- university-attendance-cost 